\title{
ORIGINAL ARTICLE \\ Botulinum toxin therapy for neurogenic detrusor hyperactivity versus augmentation enterocystoplasty: impact on the quality of life of patients with $\mathrm{SCl}$
}

\author{
C Anquetil ${ }^{1}$, S Abdelhamid ${ }^{2}$, A Gelis $^{3}$ and C Fattal ${ }^{4}$
}

Study design: Cross-sectional study.

Objectives: To compare quality of life (QoL) in patients with spinal cord injury (SCI) who underwent overactive detrusor treatment by botulinum toxin (BT) versus augmentation cystoplasty (AC).

Setting: France.

Methods: Prospective and descriptive study: Patients with a refractory overactive bladder due to SCI treated by at least two successive injections of BT or by AC. QoL was assessed using Qualiveen-30 (Q30). Clinical data and urodynamic parameters were collected.

Results: Thirty patients were included between March 2013 and March 2014: 14 in arm 1 (BT injections) and 16 in arm 2 (AC). Mean postoperative time after AC was 9.94 years. Mean BT injections already performed was 6.36. Qol was significantly lower in arm 1 -Q30 score 1.625 versus arm 2-Q30 score $1.077(P=0.037)$. Continence control was significantly higher in arm 2. Fourteen patients were completely continent (87.5\%) in arm 2 , whereas only $6(42.3 \%)$ were continent in arm $1(P=0.0187)$. Urinary infection, reflux, diverticula and stones were almost at a similar occurrence level.

Conclusions: QoL was found to be higher with an AC compared with BT injections. Long-time intervals between two injections and advantages specific to AC might explain in part these findings.

Spinal Cord (2016) 54, 1031-1035; doi:10.1038/sc.2016.49; published online 26 April 2016

\section{INTRODUCTION}

The management of urinary disorders in patients with spinal cord injury (SCI) is of prime importance to substantially reduce morbidity and mortality and preserve quality of life (QoL) and social participation. ${ }^{1}$ Patients with a complete suprasacral spinal cord lesion are usually unable to empty their bladder completely or partially and control incontinence.

Urodynamic studies show a detrusor overactivity (DO) with high pressures associated or not with a detrusor-external sphincter dyssynergia $^{2}$ and/or an impaired bladder compliance. The risk of complications such as reflux, hydronephrosis and kidney damage is high. Treatments aim at diminishing high detrusor pressures and unvoluntary detrusor contractions during the filling phase. Anticholinergic drugs typically are considered first-line therapy. If this medication is unsuccessful because of side effects or unable to adequately alleviate symptoms and reduce high detrusor pressures, ${ }^{3}$ botulinum toxin (BT) intradetrusor injections are proposed. It is a minimally invasive and a reversible treatment. The recommended total dose of $200 \mathrm{IU}$ was injected into the detrusor, sparing the trigone (10 IU for each site). In some cases, a higher dose of $300 \mathrm{IU}$ was proposed.

Considered for a long time as a second-line therapy, augmentation cystoplasty (AC) procedure is nowadays relegated to a less important position. It is dedicated to patients with an extremely reduced bladder capacity and compliance and/or an overactive bladder refractory to conservative treatments. More invasive, this technique is also irreversible. The procedure is common and involves a patch of tissue provided by a section of the small intestine and grafted onto the bladder to increase its capacity. The selected digestive segment must be detubularized. A supratrigonal cystectomy is reasonable when the detrusor is very fibrous, non-compliant and thickened. BT does not offer any benefit in this particular case.

In both treatments, intermittent catheterization is still required.

In UK, the annual number of AC procedures decreased from 192 in 2000 to 120 in 2010. Conversely, the annual number of treatment by BT intradetrusor injections increased from 50 in 2000 to 4088 in $2010 .{ }^{4}$

QoL has not been compared extensively with regard to BT injections versus $\mathrm{AC}$ in patients with SCI. As a result, the primary purpose of this study was to compare QoL of patients who underwent AC with patients who benefited from BT injections. Another objective was to know whether QoL is improved at the expense of a satisfactory urodynamic outcome?

\section{MATERIALS AND METHODS \\ Study design}

This cross-sectional study was conducted in the same spinal cord injury unit between March 2013 and March 2014. Patients received detailed oral and written information and then signed a consent form.

\footnotetext{
${ }^{1}$ CHRU Lapeyronie, Service MPR, Montpellier, France; ${ }^{2}$ Clinique Beausoleil, Service d'Urologie, Montpellier, France; ${ }^{3}$ Rehab Centre CMN Propara, Montpellier, France and ${ }^{4}$ Rehab Centre COS DIVIO, Dijon, France

Correspondence: Dr C Anquetil, PM\&R Department, CHU Lapeyronie, 371 Avenue du Doyen Gaston Giraud, Montpellier Cedex 5 34295, France.

E-mail: claire.anquetil@hotmail.fr

Received 26 August 2015; revised 17 February 2016; accepted 10 March 2016; published online 26 April 2016
} 


\section{Population}

The following inclusion criteria were defined as follows: adult patients, SCI whatever the aetiology and the level of injury, DO resistant to anticholinergic drugs and/or significant side effects of anticholinergics. They had either BT injections (two successive injections whatever the date of the last injection) or an $\mathrm{AC}$ performed at least 6 months prior to the examination.

The exclusion criteria were cognitive disorders, impossibility to interview the patients or lack of relevant documents in their medical charts.

Two arms were distinguished: arm 1 called 'BT' and arm 2 called 'AC'.

\section{Assessment}

Data were collected using individual interview with each patient and completed by the patients' medical charts:

- Demographics

- Urologic data: Methods of bladder drainage and complications

Any involuntary urine leakage (through the urethra or a cystostomy orifice) was classified as incontinence. Urinary tract complications were also collected including nonspecific effects-urinary tract complications-and specific effects-injection site haemorrhage or haematoma following BT injections and a neobladder perforation following AC.

- Urodynamic data: For the patients of arm 1 (BT), only the urodynamics tests performed between 1 and 6 months following the last injection were studied. For the patients of arm 2 (AC), the urodynamics test performed in the last 5 years preceding the study was considered.

Aggravating factors were searched: maximum detrusor pressure during filling cystometry $>40 \mathrm{~cm} \mathrm{H}_{2} \mathrm{O} ;{ }^{5}$ bladder compliance during filling cystometry $<20 \mathrm{ml}$ per $\mathrm{cm} \mathrm{H}_{2} \mathrm{O}^{6}$ The maximum cystometric bladder capacity in millilitre was also reported.

\section{- QoL assessment:}

The short version of the Qualiveen-30 questionnaire was used., ${ }^{7,8}$ Developed specifically to measure QoL of patients with SCI who have urinary disorders, it contains 30 items distributed in four domains: (a) limitations/inconvenience, (b) constraints/restrictions, (c) fears and (d) feelings/impact on daily life. Scoring is based on a 5-point Likert scale with 0 (no impact of urinary disorders on QOL) and 4 (a high adverse effect). Each domain yields an average score. An overall score is computed from the mean of the four domains. Higher is the score, lower is the QoL.

\section{Statistical analysis}

The statistical method used for comparing qualitative variables between both arms was Fisher's exact test, whereas that for comparing quantitative variables

\section{Table 1 Demographic data}

\begin{tabular}{|c|c|c|}
\hline & Arm $1 B T(\mathrm{n}=14)$ & $\operatorname{Arm} 2 A C(\mathrm{n}=16)$ \\
\hline \multicolumn{3}{|l|}{ Gender } \\
\hline Female & 3 & 11 \\
\hline Male & 11 & 5 \\
\hline Age (years), mean/s.d./range & $39 \pm 12(18-57)$ & $44.5 \pm 8.3(31-62)$ \\
\hline \multicolumn{3}{|l|}{ Level of lesion } \\
\hline Tetraplegia & 6 & 12 \\
\hline Paraplegia & 8 & 4 \\
\hline \multicolumn{3}{|l|}{ Spinal cord lesion } \\
\hline Complete lesion & 11 & 12 \\
\hline Incomplete lesion & 3 & 4 \\
\hline Duration of $\mathrm{SCl}$ (years) & $12.14 \pm 8.5(E: 5-25)$ & $20.44 \pm 9.7$ (E: 5-36) \\
\hline
\end{tabular}

was the Student's $t$-test. A difference between both arms was considered as significant if $P<0.05$.

\section{RESULTS}

\section{Demographics}

Thirty patients were included: 14 in arm 1 and 16 in arm 2 (Table 1). There were, respectively, 6 and 12 tetraplegic patients in arms 1 and 2. The other participants were all paraplegic. As males largely prevailed in arm 1 (11/14), women were predominant in arm 2 (11/16). Time since the onset of SCI was largely greater in arm 2 .

\section{Urologic data}

Most of the patients (12/14 in arm 1 and 14/16 in arm 2) carried out clean intermittent self-catheterization (Table 2). Only one patient in arm 2 was managed with an indwelling urethral catheter. Five patients in arm 1 had to use an external condom catheter and four patients in arm 1 had to use diapers. Five of the 14 patients in arm 1 and 2 of the 16 patients in arm 2 needed the assistance of an attendant to make safe transfers and to perform basic tasks such as toileting, bathing, dressing/undressing, etc. Anticholinergic drugs administration was quite similar in both arms.

In arm 1, the mean number of BT injections already performed was 6.36 (s.d.: 4.89; range: 2-18). The mean time interval between the interview and the last injection was 7.6 months (s.d.: 5.6; range: 1.5-24).

In arm 2, the mean time interval since surgery was 9.94 years (s.d.: 6.86; range 1-22). Only one patient had AC with supratrigonal cystectomy. Three patients had a combined ureteral reimplantation surgery and four a surgical treatment of effort incontinence. Ten patients benefited from a supra pubic cystostomy in the same time.

Urinary incontinence was significantly more frequent in arm 1 (BT) $-42.3 \%$ had no urine leakage - than in arm 2 (AC) $-87.5 \%$ did not have any incontinence- $P=0.0187$.

Four of the 16 patients who underwent AC had postoperative complications: parietal abscess and persistent urinary incontinence (1 patient), and neobladder perforation (1 patient). Stomal stenosis occurred in two patients. They all required a surgical revision, and in the case of a persistent urinary incontinence an antireflux reintervention was achieved. There were no complications or systemic side effects following BT injections.

Urinary lower tract infections occurred in both arms without any significant difference. Only one patient in each arm showed a vesicoureteral reflux. Bladder diverticula were observed in two patients in arm 1 and bladder stones in two patients in arm 2 (Table 3 ).

\section{Table 2 Urologic data}

\begin{tabular}{|c|c|c|c|}
\hline & $\begin{array}{l}\text { Arm } 1 \text { BT } \\
(\mathrm{n}=14)\end{array}$ & $\begin{array}{c}\text { Arm } 2 \text { AC } \\
(\mathrm{n}=16)\end{array}$ & \\
\hline \multicolumn{4}{|l|}{ Method of bladder drainage } \\
\hline Clean intermittent self catherization (CISC) & 12 & 14 & \\
\hline Clean Intermittent catheterization (CIC) & 2 & 1 & \\
\hline Indwelling catheterization & 0 & 1 & \\
\hline Condom catheter & 5 & 0 & $P=0.014$ \\
\hline Diapers & 4 & 0 & $P=0.036$ \\
\hline $\begin{array}{l}\text { Attendant help for } \mathrm{CIC} \text {, transfers and condom } \\
\text { catheter set up }\end{array}$ & 5 & 2 & $P=0.204$ \\
\hline Anticholinergic drugs & 8 & 7 & $P=0.715$ \\
\hline
\end{tabular}

Abbreviations: AC, augmentation cystoplasty; $\mathrm{BT}$, botulinum toxin injections. 
QoL

The mean Qualiveen-30 score was significantly higher in arm 1 (BT) -1.625-than in arm 2 (AC) - 1.077- $(P=0,037)$. Subscores of the following subparts-'limitations/inconvenience' and 'constraints/ restraints' were rated higher in arm 1 (Table 4).

\section{Urodynamic parameters}

All the patients of arm 2 had urodynamic tests performed in the last 5 years preceding the study. In arm 1 , eight patients had urodynamic tests performed within the 6 months after the last BT injection (Table 5). The six other patients were lost to follow-up. The average maximum cystometric bladder capacity was higher in arm 2 (AC). In all patients of arm 2, urodynamics showed an improved compliance and a low detrusor pressure following $\mathrm{AC}$, whereas in arm 1 one patient still had a persistent overactive bladder and another one a low compliance bladder.

\section{DISCUSSION}

\section{Study results}

Our study was originally designed in an attempt to answer the following question: Do BT injections and AC provide the same added value on the improvement of QoL assessed using Qualiveen-30?

Qualiveen-30 known to be responsive to the control of bladder overactivity and incontinence ${ }^{9}$ was preferred to the Short-Form 36 item Health Survey (SF-36), ${ }^{10}$ which was not dedicated to urinary disorders, or to the Incontinence Quality of life (I-QOL) scale, which was not designed specifically for neurogenic bladders patients. ${ }^{11,12}$ QoL assessment is expected to reflect the overall QoL resulting in arm 1 from the repeated and reversible treatment, including adverse or side effects, and in arm 2 from the constraints of surgery and its postoperative adverse events.

The rate of patients benefiting from intermittent catheterization was nearly similar in both arms. Arm 2 was predominantly female, and this difference with arm 1 was due to the fact that AC was mainly proposed to women unable to transfer and perform

Table 3 Secondary complications

\begin{tabular}{|c|c|c|}
\hline & Arm 1 BT $(\mathrm{n}=14)$ & Arm $2 A C(n=16)$ \\
\hline \multicolumn{3}{|c|}{ Urinary tract infection (n) } \\
\hline Absence & 4 & 3 \\
\hline 1-2/year & 1 & 5 \\
\hline$\geqslant 3 /$ year & 9 & 8 \\
\hline Vesico-ureteral reflux & 1 & 1 \\
\hline Bladder diverticula & 2 & 0 \\
\hline Bladder stones & 0 & 2 \\
\hline Kidney stones & 0 & 0 \\
\hline Bladder cancer & 0 & 0 \\
\hline
\end{tabular}

Abbreviations: AC, augmentation cystoplasty; BT, botulinum toxin injections. self-catheterization. The lowest age in arm 1 was also found to be much lower than in arm 2-that is, 18 versus 31 years. AC becoming a second-line therapy, the decision to operate was mostly taken later, a few years after undergoing medical treatments. This explains why mean age in arm 2 was greater.

Patients who underwent AC showed a better self-perceived QoL and reported a lower frequency of urinary incontinence episodes. It was essential to assess the patient's ability to control urine leakage, as patients with incontinence have usually a reduced QoL. ${ }^{10}$ Patients in arm 2 considered AC as a more reliable and an effective response to incontinence despite a postoperative morbidity in four patients and anticholinergics as a maintenance treatment in $43 \%$ of the patients.

With BT injections-arm 1-urine leakages occurred as soon as the effectiveness of BT started to decrease. The next BT injection was not always carried out early enough to prevent recurrent incontinence. The mean time interval between the interview and the last injection was 7.6 months (s.d.: 5.6; range 1.5-24). This is a very large range, and the efficacy of BT is known to decline with time. We included patients who underwent at least two injections, and we did not exclude the only patient who abided by this inclusion criterion and did not unveil any benefit. He was lost to follow-up before being questioned and was consequently assessed with a 24-month interval time.

The second part of the study aimed at identifying aggravating urodynamic factors that were likely to call into question decisionmaking in favour of one of both techniques (BT versus AC). The lack of a systematic urodynamic study in the months following the last BT injection made this analysis difficult. It would have been preferable to do it 1-6 months after the last BT injection, this period being considered as the most effective time. ${ }^{11,12}$ Mean duration of efficacy of BT is about 9 months. It improves urinary incontinence and bladder overactivity significantly, as well with 200 or 300 IU comparing with the placebo. ${ }^{12}$ Conversely in arm 2, all patients benefited from an urodynamic study performed within the last 5 years preceding the study.

Despite these methodological limits, we could observe that patients who underwent AC had higher bladder capacity. DO was absent and compliance was normal. We noticed that only one patient in arm 1 showed a persistent DO and hypercontractility associated with a reduction in compliance.

Table 5 Urodynamic parameters

\begin{tabular}{|c|c|c|}
\hline & Arm $1 B T(\mathrm{n}=8)$ & Arm $2 A C(\mathrm{n}=16)$ \\
\hline $\begin{array}{l}\text { Maximum detrusor pressure }>40 \\
\mathrm{~cm} \mathrm{H}_{2} \mathrm{O}(n)\end{array}$ & 2 & 0 \\
\hline Low compliance $(n)$ & 1 & 0 \\
\hline $\begin{array}{l}\text { Maximum cystometric bladder } \\
\text { capacity }(\mathrm{ml})\end{array}$ & $418 \pm 94(280-589)$ & $550 \pm 160(230-750)$ \\
\hline
\end{tabular}

Abbreviations: AC, augmentation cystoplasty; BT, botulinum toxin injections.

Table 4 Qualiveen-30 questionnaire

\begin{tabular}{|c|c|c|c|}
\hline & Arm $1 B T(\mathrm{n}=14)$ & Arm $2 A C(\mathrm{n}=16)$ & \\
\hline Limitations/inconvenience & $1.661 \pm 0.817(0.444-3.111)$ & $0.734 \pm 0.691(0-2.22)$ & $P=0.0027$, IC $95 \%(0.353-1.498)$ \\
\hline Constraints/restrictions & $2.170 \pm 0.876(0.875-3.875)$ & $1.539 \pm 0.763(0.25-2.75)$ & $P=0.047$, IC $95 \%(0.0101-1.251)$ \\
\hline Fears & $1.580 \pm 0.882(0.375-3.25)$ & $1.273 \pm 0.989(0-2.75)$ & $P=0.374$, IC $95 \%(-0.3892$ to 1.0031$)$ \\
\hline Feelings/impact on daily life & $1.086 \pm 0.869(0-2.2)$ & $0.762 \pm 0.972(0-2.6)$ & $P=0.345$, IC $95 \%(-0.3654$ to 1.0119$)$ \\
\hline Total score & $1.625 \pm 0.690(0.486-2.634)$ & $1.077 \pm 0.674(0.06-2.084)$ & $P=0.037$, IC 95\% (0.035-1.0599) \\
\hline
\end{tabular}

Abbreviations: AC, augmentation cystoplasty; BT, botulinum toxin injections. 


\section{Comparison with literature data}

Overactive neurogenic bladder with or without detrusor-external sphincter dyssynergia is a common issue in people with SCI. It remains a major source of morbidity. In the 1990s, AC with catheterizable stoma had positively modified the management of incontinence due to an overactive bladder. During recent years, there is no doubt that BT injections have revolutionized the treatment of intractable overactive bladder and have largely supplanted surgery. In some cases, BT injections are only carried out to postpone surgery.

To our knowledge, there are no studies comparing at once QoL, continence and urodynamic parameters in patients with SCI who underwent either BT injections or augmentation bladder cystoplasty. Most of the studies deal with the efficacy of both treatments independently of each other.

QoL was found to be excellent in 26 of 27 patients (96.2\%) on average 6 months postoperatively following an AC. ${ }^{13}$ Quek and Ginsberg $^{14}$ showed in 26 patients a long-term effect of the AC procedure with a mean duration of 8 years-range: $4-13$ years. They confirmed the persistence of a high bladder capacity and the reduction in high bladder pressures during filling. Sixty-nine per cent of the included patients did not complain about any incontinence, $27 \%$ had urine leakage once a month or once a week and $4 \%$ had a permanent incontinence. The authors noticed that only two patients (8\%) were still treated with anticholinergics. Biers et al. ${ }^{4}$ in a literature review underlined the high rate of 'satisfactory results' resulting from the AC procedure-on average $77 \%$ (range: $55-88 \%) .{ }^{4}$ Herschorn and Hewitt reported adverse effects in 24 out of 59 patients (40.6\%). Twenty-one per cent were operated once again. ${ }^{15}$ A randomized controlled study related to BT injections showed better results and a significantly greater I-QoL score in patients who underwent BT detrusor injections compared with patients who did not have any treatment $(P<0.001) .{ }^{11}$ No statistically significant difference in overall QoL was observed between both comparative groups with respect to the BT dose (200 versus $300 \mathrm{IU})$. Other studies showed urodynamic evidence of effectiveness of BT injections. Kuo et al. ${ }^{16}$ reported a significant reduction in the maximum detrusor pressure from $39.8 \pm 21.7$ to $20.6 \pm 19.1 \mathrm{~cm} \mathrm{H}_{2} \mathrm{O}(P<0.05)$ after four BT injections repeated at intervals of 6 months. Compliance increased significantly from $26.9 \pm 26.8$ to $40.1 \pm 24.1(P<0.035)$. In a literature review on BT injections, Karsenty et al. ${ }^{17}$ reported response rates varying from 42 to $87 \%$ in different studies- $42.3 \%$ in our study. QoL was assessed at baseline and 12-24 weeks after treatment. Improvement rates were 35 and $65 \%$, respectively. Schurch et al. compared the urodynamic efficacy of BT, at 24 weeks, in two arms: 200 versus 300 units. There was a significant decrease in mean maximum detrusor pressure after treatment estimated 38.7 and $35.5 \%$, respectively. ${ }^{12}$ Moreover, I-QoL significantly improved in both arms compared with the placebo group $(P<0.002)$. The level of improvement was maintained through 24 weeks. $^{18}$

Finally, only one study compared BT and AC. Padmanabhan et al. ${ }^{19}$ carried out a 5-year analysis of BT injections and AC for refractory neurogenic DO. On the basis of an AC complication rate of $40 \%$, BT was found to be more cost effective over 5 years if the effects lasted for $\geqslant 5.1$ months. Conversely, AC was proved to be cheaper than $\mathrm{BT}$ when the cost of $\mathrm{BT}$ increased or the $\mathrm{AC}$ complication rate was dropped below $14 \%$.

The effect on QoL and continence of repeated and long-term BT injections in paraplegics with refractory neurogenic overactivity cannot be denied. Paradoxically, our study reported that QoL in patients who had undergone AC was higher. Various reasons can explain this finding:

- A higher risk of episodes of incontinence between active treatments. Time with adequate control of urinary leakage cannot be predicted. It is quite difficult to plan for next injection on time without any risk of urine leakage between two injections.

- The increasing number of patients benefiting from BT injections makes it difficult for the surgeons to plan the BT reinjections at the best time.

- A 'treatment dependency' due to the periodical need of BT reinjections can be a limiting factor for a successful adherence of the patient.

- When urine leakages occur during the interval time between two injections, it is often difficult to determine whether they are the result of a loss of BT efficacy or the consequence of an irritating stimulus.

To improve medical benefit in patients who recover a controlled continence and fear the occurrence of a recurrent urinary incontinence, BT reinjection should be carried out as soon as the effects are less effective.

Literature data underline a satisfactory urodynamic response of the overactive bladder to BT injections, offering in patients with SCI a real therapeutic alternative to surgery, repeatable prior to a potential AC procedure and even acceptable as a long-term treatment. ${ }^{20}$ Actually, some patients may require an AC procedure at an early stage. It offers advantages compared with BT: a more efficient prevention of urinary incontinence, and when a continent cystostomy is combined the possibility for the patient with SCI to perform clean intermittent selfcatheterization without transferring from wheelchair to bed and the opportunity for patients with low and middle-level tetraplegia to selfcatherize.

\section{Limitations of the study}

There are two potential biases in our study: the small sample sizes in both arms and the fact that the subjects were not randomized to the two treatments. Despite these limitations, we stress that these results are suggestive enough to justify a further larger study and a randomized controlled trial.

\section{CONCLUSIONS}

Intradetrusor BT injections and $\mathrm{AC}$ have a positive impact both on QoL and on incontinence. The urodynamic risk is low in both groups of patients. QoL was found to be higher with an AC procedure compared with BT injections. Time intervals between two injections might be too long when BT starts to be less effective. Advantages in favour to AC could also explain in part this paradoxical finding. A prospective and multicentre study in a greater number of patients with SCI is expected to confirm these results.

\section{DATA ARCHIVING}

There were no data to deposit.

\section{CONFLICT OF INTEREST}

The authors declare no conflict of interest.

\section{AUTHOR CONTRIBUTIONS}

Study concept and design: CA, CF, AG and SA; acquisition of data and analysis of data: CA and CF; interpretation of data: CA; drafting of manuscript: CA and SA; study supervision and English translation: CF. 
1 Frankel HL, Coll JR, Charlifue SW, Whiteneck GG, Gardner BP, Jamous MA et al. Long-term survival in spinal cord injury: a fifty year investigation. Spinal Cord 1998; 36: 266-274.

2 Haab F, Amarenco G, Coloby P, Grise P, Jacquetin B, Labat J. Terminologie des troubles fonctionnels du bas appareil urinaire: adaptation française de la terminologie de I'International Continence Society. Prog Urol 2004; 14: 1103-1111.

3 De Seze M, Ruffion A, Haab F, Chartier-Kastler E, Denys P, Game X. Recommandations de bonne pratique clinique pour le suivi des patients neurologiques après injection de toxine botulique intradétrusorienne. Pelv Perineol 2009; 4: 53-59.

4 Biers SM, Venn SN, Greenwell TJ. The past, present and future of augmentation cystoplasty. BJU Int 2012; 109: 1280-1293.

5 McGuire EJ, Woodside JR, Borden TA, Weiss RM. Prognostic value of urodynamic testing in myelodysplastic patients. J Urol 1981; 126: 205-209.

6 Hackler RH, Hall MK, Zampieri TA. Bladder hypocompliance in the spinal cord injury population. J Urol 1989; 141: 1390-1393.

7 Costa P, Perrouin-Verbe B, Colvez A, Didier J, Marquis P, Marrel A et al. Quality of life in spinal cord injury patients with urinary difficulties. Development and validation of qualiveen. Eur Urol 2001; 39: 107-113.

8 Bonniaud V, Parratte B, Amarenco G, Jackowski D, Didier JP, Guyatt G. Measuring quality of life in multiple sclerosis patients with urinary disorders using the Qualiveen questionnaire. Arch Phys Med Rehabil 2004; 85: 1317-1323.

9 Pannek J, Kullik B. Does optimizing bladder management equal optimizing quality of life? Correlation between health-related quality of life and urodynamic parameters in patients with spinal cord lesions. Urology 2009; 74: 263-266.

10 Liu CW, Attar KH, Gall A, Shah J, Craggs M. The relationship between bladder management and health-related quality of life in patients with spinal cord injury in the UK. Spinal Cord 2010; 48: 319-324.

11 Sussman D, Patel V, Del Popolo G, Lam W, Globe D, Pommerville P. Treatment satisfaction and improvement in health-related quality of life with onabotulinum toxin $A$ in patients with urinary incontinence due to neurogenic detrusor overactivity. Neurourol Urodyn 2013; 32: 242-249.

12 Schurch B, de Seze M, Denys P, Chartier-Kastler E, Haab F, Everaert K et al. Botulinum toxin type $\mathrm{a}$ is a safe and effective treatment for neurogenic urinary incontinence: results of a single treatment, randomized, placebo controlled 6-month study. J Urol 2005; 174: 196-200.

13 Khastgir J, Hamid R, Arya M, Shah N, Shah PJ. Surgical and patient reported outcomes of 'clam' augmentation ileocystoplasty in spinal cord injured patients. Eur Urol 2003; 43: 263-269.

14 Quek ML, Ginsberg DA. Long-term urodynamics followup of bladder augmentation for neurogenic bladder. J Urol 2003; 169: 195-198.

15 Herschorn S, Hewitt RJ. Patient perspective of long-term outcome of augmentation cystoplasty for neurogenic bladder. Urology 1998; 52: 672-678.

16 Kuo HC, Liu SH. Effect of repeated detrusor onabotulinumtoxinA injections on bladder and renal function in patients with chronic spinal cord injuries. Neurourol Urodyn 2011; 30: 1541-1545.

17 Karsenty G, Denys P, Amarenco G, De Seze M, Game X, Haab F et al. Botulinum toxin A (Botox) intradetrusor injections in adults with neurogenic detrusor overactivity/ neurogenic overactive bladder: a systematic literature review. Eur Urol 2008; 53: 275-287.

18 Karsenty G, Reitz A, Lindemann G, Boy S, Schurch B. Persistence of therapeutic effect after repeated injections of botulinum toxin type $A$ to treat incontinence due to neurogenic detrusor overactivity. Urology 2006; 68: 1193-1197.

19 Padmanabhan P, Scarpero HM, Milam DF, Dmochowski RR, Penson DF. Five-year cost analysis of intra-detrusor injection of botulinum toxin type $A$ and augmentation cystoplasty for refractory neurogenic detrusor overactivity. World J Urol 2011; 29: 51-57.

20 Perrouin-Verbe B, Ruffion A, Game X, Denys P, Kerdraon J, Karsenty G et al. [Criteria and best clinical practice guidelines for first intradetrusor injection of botulinum toxin type A to treat neurogenic detrusor overactivity]. Prog Urol 2009; 19: 372-382. 